\title{
RECONHECER E TRADUZIR TRAÇOS DE SÊNECA EM SHAKESPEARE
}

\author{
José Eduardo dos Santos Lohner* \\ Universidade de São Paulo
}

Renata Cazarini de Freitas ${ }^{* *}$

Universidade de São Paulo

Resumo: O filósofo Sêneca (c.4 a.C.-65 d.C.) é autor de oito tragédias latinas às quais se atribui, regra geral, elevado grau de "influência" na literatura dramática produzida na Inglaterra da virada do século XVI para o XVII. Sem recorrer ao usual método de localizar citações ou equivalências textuais, propõe-se aqui reconhecer os traços da elocução senequiana em Shakespeare a partir da identificação de dispositivos da retórica antiga e de suas correspondências em cenas específicas de Richard III, Hamlet e The Tempest. Uma tradução dessas peças a partir do latim ou do inglês deve refletir o domínio e a intenção dos autores no uso de tais expedientes retóricos.

Palavras-chave: Sêneca. Shakespeare. Retórica. Tradução. Latim.

\footnotetext{
* Possui graduação em Letras (Português e Latim) pela Universidade de São Paulo (1988) e doutorado em Letras Clássicas pela Universidade de São Paulo (2000). Atualmente é Professor Doutor, ms-3, em RDIDP, da Universidade de São Paulo (USP). São Paulo, SP, Brasil. E-mail: jelohner@usp.br

** É graduada em Latim pela USP (2012) e graduada em Comunicação Social, com habilitação em Jornalismo, pela Faculdade Cásper Líbero (1990). Mestranda do programa de Pós-graduação em Letras Clássicas da Universidade de São Paulo (USP). São Paulo, SP, Brasil. E-mail: renatacdef@gmail.com
} 


\title{
IDENTIFYING AND TRANSLATING SENECAN FEATU- RES IN SHAKESPEARE'S PLAYS
}

\begin{abstract}
Seneca, the philosopher (ca.4 BC-65 AD) wrote eight Latin tragedies which are usually taken as having had a significant influence on Elizabethan and the Jacobean drama. Without resorting to the usual method of locating quotes or textual equivalences, this paper aims at recognizing some of Seneca's elocutionary features in Shakespeare's plays by identifying ancient devices of Rhetoric and their correspondences in specific scenes from Richard III, Hamlet and The Tempest. Any translations of these dramas from the Latin or the English into Portuguese should reflect the ability and the intent of both authors in handling such rhetorical expedients.
\end{abstract}

Keywords: Seneca. Shakespeare. Rhetoric. Translation. Latin.

\section{Introdução}

Quem estuda o teatro latino, em particular a tragédia, se depara sempre com a situação de um corpus relegado pelos encenadores e pelos atores. Parcialmente, até mesmo pelos classicistas. É fácil verificar que as peças gregas antigas - de Ésquilo, Sófocles, Eurípides e as comédias de Aristófanes - são traduzidas e encenadas com frequência. Por exemplo, a Medeia de Eurípides tem pelo menos quatro traduções contemporâneas do grego para o português do Brasil publicadas em livro. Já a Medeia latina, de Sêneca, conta apenas uma tradução em livro no Brasil, de 1955, depois reeditada, mas esgotada há anos. ${ }^{1}$

Lúcio Anneu Sêneca (c.4 a.C.-65 d.C.) nasceu em Córdoba, na antiga colônia latina chamada "Hispânia". Viveu em Roma, onde chegou a senador e preceptor do imperador Nero, com quem ele rompeu e por quem foi, supostamente, obrigado a cometer suicídio após acusação de envolvimento num golpe político. Sêneca é reconhecido também por ter sido um propagador do estoicismo, escola filosófica de origem grega que defende a prevalência da 
razão sobre as paixões. Essas ideias foram registradas por Sêneca num conjunto de cartas e em textos filosóficos que chegaram, em parte, até nós.

A ele também é atribuído um corpus de dez peças (embora a autoria de duas delas hoje seja questionada), as únicas tragédias antigas latinas restantes, já que de outros dramaturgos que escreveram em latim temos apenas fragmentos. Entre as peças de Sêneca, estão algumas a que se faz referência frequentemente nos estudos que tratam das possíveis fontes em que William Shakespeare (1564-1616) teria bebido: Troianas, Tiestes, Hércules louco, Agamêmnon.

É preciso dizer que, de maneira alguma, é consensual que Shakespeare tenha sido influenciado por Sêneca de forma direta. ${ }^{2}$ Uma parte dos pesquisadores buscou, sem sucesso, provas de que o poeta inglês tivesse lido as tragédias senequianas no original latino. Nem mesmo está documentada a frequência de Shakespeare na escola de meninos (Grammar School) de Stratford-upon-Avon, sua terra natal, mas supõe-se que lá ele tenha estudado retórica, entrando em contato direto com autores latinos clássicos, como era a tradição no final do século XVI, quando a Inglaterra adotava um currículo baseado nas propostas educacionais de Erasmo de Roterdã.

Um livro de referência sobre esse tema é de T. W. Baldwin (1944), em que o autor investiga a formação escolar do dramaturgo, motivado pelo conhecido comentário do poeta Ben Jonson (1572-1637) de que Shakespeare teria "small Latine and lesse Greeke” - ou seja, pouquíssima formação clássica. A conclusão do pesquisador é que, de fato, teria sido apenas regular a formação de Shakespeare quanto aos clássicos antigos, mas essa não é uma tese aceita sem restrições. ${ }^{3} \mathrm{O}$ que os registros ingleses - escolares e editoriais - mostram é que Terêncio, comediógrafo latino, era tema de manuais de ensino do latim. ${ }^{4}$

De qualquer forma, Baldwin traz no seu livro uma informação útil para a discussão: os meninos ingleses tinham em seu currículo um livro referencial de retórica chamado, em latim, Ad Herennium. A "Retórica a Herênio" (2005) é um compêndio para a formação 
de oradores - em particular, advogados na Roma antiga. No livro IV dessa obra, dedicado à elocução, apresenta-se um estudo sobre as figuras de linguagem, tema muito valorizado no Renascimento.

Vários procedimentos de ornamentação da linguagem, identificáveis em Sêneca e em Shakespeare, geram efeitos análogos, mas isso não é suficiente para vincular um autor ao outro.

\section{Tragédias em vernáculo}

A tragédia senequiana teve seu espaço na Inglaterra elisabetana, com encenações em latim nas universidades de Cambridge e Oxford e, em língua vernácula, por meio de adaptações dessas peças feitas pelos University Wits, dramaturgos com formação universitária, diferentemente de Shakespeare. Como escreveu o historiador Arnaldo Momigliano acerca das influências latinas na Europa do final do século XVI, "a popularidade de Sêneca tanto como estilista quanto como filósofo estava em alta; o neoestoicismo tornara-se a fé daqueles que, sem ter perdido a fé por completo, tinham perdido a paciência com a teologia" ${ }^{5}$ (MOMIGLIANO, 2004, p. 175).

Para exemplificar: a tragédia Troianas havia sido traduzida para o inglês em 1559, e as demais, na sequência. Houve várias edições do volume que reunia as dez tragédias traduzidas, conhecidas como Tenne Tragedies, de 1581, a primeira edição completa de peças publicada na Inglaterra (embora não fosse um projeto coletivo), antecipando os Works de Ben Jonson (1616) e até mesmo o first folio, de Shakespeare (1623). ${ }^{6}$

A presença de Sêneca era tão constante que Thomas Nashe (1567-1601), um dos University Wits, escreveu uma célebre crítica a essas traduções no Preface to Greene's Menaphon (1589) ${ }^{7}$ : "English Seneca read by candle-light yields many good sentences, as Blood is a beggar, and so forth; and if you entreat him fair in a frosty morning, he will afford you whole Hamlets, I should say handfuls of tragical speeches." 
Não se sabe se essa frase se refere a uma versão antiga da peça mesma de Shakespeare (o famoso Hamlet tem datação incerta entre 1599 e 1602) ou a um texto que a teria antecedido, talvez de autoria de Thomas Kyd - o suposto ur-Hamlet.

Em um artigo estimulante, Jessica Winston (2006, p. 30) propõe que a recepção elisabetana de Sêneca seja analisada como tendo ocorrido em duas etapas:

The first took place in the 1560s. Prior to this decade there was little concern with Seneca in England, with only a handful of philosophical works and fragments of the drama published in manuscript and print. Beginning in 1559, however, there was intense interest in the author, especially at the universities and early English law schools, the Inns of Court, where students and fellows translated most of the drama and performed a series of Senecan and neo-Senecan plays. The later phase took place in the 1580 s and 1590 s when, after a decade long break in the performance and publication of Seneca, Thomas Newton compiled the first English anthology of the Tenne Tragedies (1581), and Thomas Kyd, Christopher Marlowe, and Shakespeare adapted elements of the drama for their plays.

$\mathrm{O}$ argumento central de Winston é que os primeiros, por assim dizer, seguidores de Sêneca o absorveram ao máximo, enquanto dramaturgos da segunda fase aproveitaram alguns "aspectos" das peças. $\mathrm{O}$ foco do artigo de Winston é a primeira etapa, a dos tradutores das tragédias senequianas. Contudo, em termos gerais, pode-se afirmar que um pesquisador familiarizado com a obra dramática e o estilo de Sêneca, ao se debruçar sobre os textos shakespearianos, vai encontrar paralelos com as peças latinas.

Mas o objetivo não deve ser localizar passagens textuais que se repitam. Assim como Sêneca, Shakespeare trabalhava sobre matéria já conhecida e praticava a aemulatio, a emulação, ou seja, a 
imitação com a intenção de superar o modelo. Não se tratava de imitação servil. Até mesmo as traduções eram resultado de apropriação criativa dos originais senequianos.

\section{Heavy Seneca}

Existe um tom jocoso nas palavras de Polônio, conselheiro-bufão do rei da Dinamarca e pai de Ofélia, o qual Hamlet mata involuntariamente, no entanto, é a ele que cabe a menção a Sêneca na obra shakespeariana. Ele diz em Hamlet, Ato II, cena 2, vv.412-3: "Seneca cannot be too heavy, nor Plautus too light", referindo-se à variedade de papeis que a trupe de atores que chegou a Elsinore pode desempenhar. Entre os ideais da tragédia e da comédia latinas, Polônio lista os gêneros mistos que tomaram os palcos ingleses à época de Shakespeare, e esses atores podem fazer de tudo. Importante notar que a menção a Sêneca aparece desde o Primeiro in-quarto. ${ }^{8}$

Além do substrato estoico, dispositivos retóricos de que Sêneca lançou mão são localizados pelos pesquisadores principalmente na fase inicial de Shakespeare, nos dramas históricos, como Richard III. Ali, são patentes construções de diálogos de confrontação análogas às das peças de Sêneca. Mas em Hamlet encontram-se também traços do autor latino, como a self-dramatization nos solilóquios. Na fase final da carreira, em The Tempest há ainda indícios da elocução senequiana na invocação a divindades por Próspero.

Deve-se atentar que imagens costumeiramente associadas ao teatro senequiano, como o espectro, a desordem das forças da natureza e cenas tingidas de sangue já haviam sido incorporadas como recursos dramatúrgicos em textos em língua vernácula, nas chamadas revenge tragedies. 


\section{Richard III}

Comentadores costumam citar Henry VI Part III e Richard III como os principais exemplos do emprego, em Shakespeare, da "esticomitia", uma convenção da poesia dramática antiga que consiste na alternância de falas, verso a verso, entre duas personagens, usualmente em diálogos de forte caráter agonístico. O primeiro registro desse termo técnico de origem grega remonta ao século II d.C, na obra Onomasticon, de Júlio Pólux, mas o expediente já era utilizado na dramaturgia ática clássica do século V a.C. Autores latinos que antecederam Sêneca, como Ênio (239-169 a.C.), Pacúvio (c.220-132 a.C.) e Ácio (170-c.90 a.C.), também recorreram à esticomitia, pelo que se depreende dos fragmentos de suas obras. Em Sêneca, o emprego desse recurso evoca não só a linguagem tradicional do drama, mas também a prática oratória dos tribunais e do Senado romano, onde o dispositivo retórico da altercatio era usado vigorosamente. ${ }^{9}$

Ele faz uso da retomada de palavras-chave da fala de um personagem (catch-word) por seu antagonista, distorcendo-as ou esvaziando-as de sentido. Um número expressivo de figuras de linguagem e ainda as características sententiae (máximas) senequianas configuram esse discurso dialógico de grande efeito patético (pathos). Recurso adicional para a elevação da tensão é a divisão de um só verso entre os antagonistas, a chamada "antílabe". Em algumas peças de Sêneca, um só verso chega a ser distribuído em quatro falas. ${ }^{10}$ Essa elocução senequiana - anacronicamente, o "estilo do autor" - pode ser capturada em Richard III, Ato I, cena 2, vv.107-129, em que as palavras retomadas estão destacadas:

\section{LADY ANNE}

[...]

$\mathrm{O}$, he was gentle, mild and virtuous! 
The better for the King of heaven, that hath him

\section{LADY ANNE}

He is in heaven, where thou shalt never come.

\section{GLOUCESTER}

Let him thank me, that holp to send him thither, For he was fitter for that place than earth.

\section{LADY ANNE}

And thou unfit for any place but hell.

GLOUCESTER

Yes, one place else, if you will hear me name it.

\section{LADY ANNE}

Some dungeon.

\section{GLOUCESTER}

Your bed-chamber.

\section{LADY ANNE}

I'll rest betide the chamber where thou liest!

\section{GLOUCESTER}

So will it, madam, till I lie with you.

\section{LADY ANNE}

I hope so.

\section{GLOUCESTER}

I know so. But, gentle Lady Anne,

To leave this keen encounter of our wits, And fall somewhat into a slower method: Is not the causer of the timeless deaths Of these Plantagenets, Henry and Edward, As blameful as the executioner? 


\section{LADY ANNE}

Thou wast the cause and most accursed effect.

\section{GLOUCESTER}

Your beauty was the cause of that effect

Your beauty, that did haunt me in my sleep

To undertake the death of all the world,

So I might live one hour in your sweet bosom. ${ }^{11}$

Uma interessante característica desse trecho é a referência explícita de Gloucester à troca rápida e mordaz. Tanto em Sêneca como em Shakespeare, os protagonistas são retratados como mestres do discurso. No exemplo, Richard, ainda duque de Gloucester, da casa dos York, e Lady Anne, viúva do príncipe Edward, da casa dos Lancaster, em meio às Guerras das Rosas (1399-1485), altercam quanto ao assassinato do rei Henry VI, sogro de Anne. Note-se como Richard conduz o diálogo, numa exibição de habilidade oratória, e - como se sabe - seduz por fim a antagonista. ${ }^{12}$

Comparação com um trecho de peça senequiana se faz necessária para evidenciar a proximidade da elocução dos dois autores. Excerto de Medeia, vv.159-170, rico em exemplos de esticomitia, antílabe, disticomitia (versos duplos), sententiae: ${ }^{13}$

\section{MEDEA}

Fortuna fortes metuit, ignauos premit.

\section{NVTRIX}

Tunc est probanda, si locum uirtus habet.

MEDEA

Numquam potest non esse uirtuti locus.

\section{MEDEIA}

A Fortuna teme os fortes e oprime os fracos.

\section{AMA}

A coragem é bem-vinda quando é o momento.

\section{MEDEIA}

Nunca é descabido um momento de coragem. 


\section{NVTRIX}

Spes nulla rebus monstrat adflictis uiam.

\section{MEDEA}

Qui nil potest sperare desperet nihil.

\section{NVTRIX}

Abiere Colchi, coniugis nulla est fides

Nihilque superest opibus

e tantis tibi.

\section{MEDEA}

Medea superest: hic mare

et terras uides

ferrumque et ignes et

deos et fulmina.

NVTRIX

Rex est timendus.

\section{MEDEA}

Rex meus fuerat pater.

NVTRIX

Non metuis arma?

\section{MEDEA}

Sint licet terra edita.

NVTRIX

Moriere.

\section{AMA}

Não há esperança apontando saída dessas aflições.

\section{MEDEIA}

Quem nada pode esperar de nada deve desesperar.

\section{AMA}

Os colcos se foram, a fidelidade do teu marido é nula e nada te resta de tua vasta riqueza.

\section{MEDEIA}

Resta Medeia: aqui vês mar e terras, e ferro e fogo, e deuses e raios.

\section{AMA}

$\mathrm{O}$ rei deve ser temido.

\section{MEDEIA}

Foi rei o meu pai.

\section{AMA}

Não temes as armas?

\section{MEDEIA}

Nem que brotem da terra.

\section{AMA}

Morrerás. 


\section{MEDEA}

Cupio.

NVTRIX

Profuge.

MEDEA

Paenituit fugae.

\section{MEDEIA}

Desejo-o.

AMA

Foge!

\section{MEDEIA}

Arrependi-me da fuga.

A leitura atenta desses excertos permite ensaiar algumas considerações sobre sua tradução: é indispensável a repetição das palavras-chave, configurando a retomada; a opção por frases curtas descortina a agilidade da troca esticomítica; trata-se de registro característico de oralidade, porém elevado.

\section{Hamlet}

Partindo mais uma vez da Medeia (vv.1-55), é possível rastrear Sêneca em Hamlet, por exemplo, no solilóquio do Ato II, cena 2, vv.560-617, que se segue aos preparativos da encenação da peça encomendada pelo príncipe para desmascarar o rei, tio, padrasto, assassino. O protagonista revela insatisfação consigo próprio por não sentir a paixão pela vingança tão cobrada pelo fantasma do pai. $\mathrm{Na}$ peça latina, a vingança é central: Medeia mata os dois filhos que tem com Jasão depois de ter sido trocada por outra mulher e foge no carro-de-fogo do Sol, seu avô. Pode-se afirmar que, em ambas as peças, esses "vingadores" atrelam a própria identidade à execução do ato de revanche. Medeia busca resgatar-se como bárbara depois de submetida por anos à cultura grega; Hamlet tenta posicionar-se entre a rude tradição nórdica e a nova cultura da razão.

Os paralelos entre os dois solilóquios podem ser observados, considerando-se as partes do discurso na retórica antiga, tanto a 
partir de tópicos (inuentio) como da elocução (elocutio) e, parcialmente, da estrutura (dispositio). Em ambos os textos, com pouco menos de 60 versos cada, o tema principal é passar das palavras à ação. Explicitamente nos versos 597-8 de Hamlet e 25-8 da Medeia aparecem os termos "palavras" (words/uerba) e "vingança" (revenge/ultio). Ademais, Medeia praticamente encerra seu solilóquio com uma autoinvocação para pôr fim imediato a protelações (v.54: rumpe iam segnes moras), tema que é, sabidamente, fulcral em Hamlet.

\section{HAMLET, Ato II, cena 2, vv.595-9}

Why, what an ass am I! Ay, sure, this is most brave, That I, the son of the dear murdered, Prompted to my revenge by heaven and hell, Must like a whore unpack my heart with words And fall a-cursing, like a very drab, a scullion!

\section{MEDEIA, vv.25-31}

parta iam, parta ultio est:

peperi. Querelas uerbaque in cassum sero?

non ibo in hostes? manibus

excutiam faces

caeloque lucem - spectat hoc

nostri sator

Sol generis, et spectatur, et curru insidens per solita puri spatia decurrit poli? non redit in ortus et remetitur diem?
Concebida, foi concebida a vingança: eu a pari. Queixas e palavras semeio ao vento? Não irei contra o inimigo? De suas mãos, tomarei os fachos e, do céu, a luz. O patriarca de minha raça, o Sol, isto vê e ainda se deixa ver: assentado no seu carro percorre como sempre a amplitude do céu claro? Não retorna ao nascente e reverte o dia?

O personagem instiga-se a agir. Compare Medeia (v.41: si uiuis, anime/se é que vives, meu espírito) e Hamlet (v.600: About, 
my brain!). Mais à frente, Medeia quer afastar os temores femininos (v.42: pelle femineos metus) e Hamlet lamenta ser uma alma sensível e faltar-lhe o rancor para agir (v.589: but I am pigeon-livered and lack gall). Note-se a imagem de entranhas em Medeia v.40 e em Hamlet v.592.

Esses são alguns tópicos em comum, e se atestam ainda figuras de linguagem, ou ornamentos de palavras, segundo a nomenclatura da retórica antiga, tal como aparecem no livro Ad Herennium. O decoro no uso dessas figuras é que faz o melhor orador, mas, no texto teatral, o efeito patético depende muita vez de uma elocução mais contundente. Assim, a interrogatio, sequenciamento de perguntas que não necessariamente têm respostas, é listada no manual como "nem sempre grave e harmoniosa" (Rhet. Her. IV.22, p.231) e recomendada ao orador apenas para confirmar alegações anteriores. Nos solilóquios, porém, parece funcionar adicionalmente como marca da condição meditativa do personagem. Veja o trecho acima de Medeia e o excerto abaixo:

\section{HAMLET, Ato II, cena 2, vv. 570-3}

What's Hecuba to him, or he to Hecuba, That he should weep for her? What would he do Had he the motive and the cue for passion That I have?

Outra figura é o articulus, uma sucessão breve de palavras separadas por pausa, "num discurso entrecortado" (Rhet. Her. IV.26, p. 239). A imagem que descreve este ornamento é totalmente adequada ao efeito que Sêneca e Shakespeare conseguem causar: "parece que o corpo é apunhalado com várias e rápidas investidas" (Rhet. Her. IV.26, p.239). 


\section{MEDEIA, vv.20-2}

uiuat! per urbes erret ignotas Que ele viva! Vague por cidades egens

exul pauens inuisus incerti laris, iam notus hospes limen alienum expetat; estranhas, pobre, exilado, temeroso, repudiado, sem lar, hóspede notório que anseie por porta alheia;

HAMLET, Ato II, cena 2, vv.591-3

I should have fatted all the region kites

With this slave's offal: bloody, bawdy villain!

Remorseless, treacherous, lecherous, kindless villain!

As inflexões que resultam do uso dessas figuras, se preservadas na tradução, resgatam uma voz convulsionada, um personagem em meio a um dilema em conversa consigo mesmo, o que constitui propriamente o solilóquio. ${ }^{14}$

Para apontar também as diferenças, uma importante figura no segmento de Medeia é a repetitio ou anáfora (v.13: nunc, nunc; v.32: $d a, d a)$. Embora presente em outros trechos de Hamlet, ela não ocorre neste solilóquio. Por outro lado, há apenas na fala de Hamlet o recurso à exclamatio, expressão de dor ou indignação ao invocar algo ou alguém, na forma da invocação a ele mesmo na primeira pessoa:

HAMLET, Ato II, cena 2, vv.591-3

$\mathrm{Oh}$, what a rogue and peasant slave am I!

HAMLET, Ato II, cena 2, vv.591-3

Why, what an ass am I!

Quanto à estrutura, o solilóquio de Medeia é organizado da seguinte maneira: invocação (euocatio), súplica (obsecratio), prodígio 
(prodigium), arrazoado (ratiocinatio), máxima (sententia). O solilóquio de Hamlet espelha apenas em parte essa disposição, explorando o prodígio e o arrazoado. Já a invocação senequiana ecoa claramente em The Tempest - não sem um véu de ironia, como se verá.

Enquanto Medeia invoca a ajuda de grandes divindades nos primeiros 18 versos do solilóquio, Hamlet busca inspiração no extraordinário ator que acaba de representar a rainha derrotada de Troia, Hécuba, também nos primeiros 18 versos. São as façanhas desse ator no palco que constituem o prodígio, o maravilhoso. Para Medeia, são as proezas que julga capaz de fazer assumindo o carro-de-fogo do Sol.

$\mathrm{O}$ arrazoado é a inquirição de si mesmo sobre o que vem sendo afirmado, é a exposição do desenvolvimento de um raciocínio, um fundamento do solilóquio. Com esse dispositivo, Sêneca e Shakespeare encerram os solilóquios.

\section{HAMLET, Ato II, cena 2, vv.600-17}

Fie upon't, foh! About, my brain! I have heard That guilty creatures sitting at a play

Have by the very cunning of the scene Been struck so to the soul that presently They have proclaimed their malefactions:

For murder, though it have no tongue, will speak With most miraculous organ. I'll have these players

Play something like the murder of my father Before mine uncle: I'll observe his looks, I'll tent him to the quick: if he but blench, I know my course. The spirit that I have seen May be the devil, and the devil hath power $T$ ' assume a pleasing shape, yea, and perhaps, Out of my weakness and my melancholy, As he is very potent with such spirits, Abuses me to damn me. I'll have grounds 
More relative than this: the play's the thing Wherein I'll catch the conscience of the king.

\section{MEDEIA, vv.37-55}

Hoc restat unum, pronubathalamo feram

ut ipsa pinum postque sacrificas preces

caedam dicatis uictimas altaribus. per uiscera ipsa quaere supplicio uiam,

si uiuis, anime, si quid antiqui tibi remanet uigoris; pelle femineos metus

et inhospitalem Caucasum mente indue.

quodcumque uidit Phasis aut

Pontus nefas,

uidebit Isthmos. effera ignota horrida

tremenda caelo pariter ac terris mala

mens intus agitat: uulnera et caedem et [uagum

funus per artus - leuia memoraui nimis:

haec uirgo feci; grauior exurgat dolor:

maiora iam me scelera post partus decent.

accingere ira teque in exitium para furore toto. paria narrentur tua repudia thalamis: quo uirum linques modo?
É isto que falta: que eu mesma leve ao tálamo a chama nupcial e, feitas as preces para o sacrifício, golpeie as vítimas no altar consagrado.

Através das vísceras, indaga o curso para a punição, meu espírito, se é que vives, se algo do antigo vigor persiste em ti. Expulsa os temores femininos e inculca em ti o bárbaro Cáucaso.

Todo sacrilégio que o Fásis e o Ponto viram, o Istmo verá. Ferozes, inauditos, horrendos males que fazem juntos tremer céu e terra, esta mente trama: feridas e assassínio e o funeral disperso de um corpo em pedaços.

É leve demais o que mencionei: fiz isto quando virgem. Que mais grave seja meu rancor: crimes maiores condizem comigo depois que dei à luz.

Arma-te da ira e prepara-te para o extermínio com furor total. Que se narre tua separação tal qual teu casamento. Como deixarás o marido? 
hoc quo secuta es. rumpe iam segnes moras:

quae scelere parta est, scelere linquenda est [domus.
Como o seguiste.

Põe fim a protelações: casa nascida em crime, com um crime há que deixá-la.

Exceto pelo caráter de máxima no desfecho do solilóquio de Medeia, os arrazoados têm elementos análogos - a autoinvocação, o encadeamento das ações planejadas, a reflexão sobre a eficácia da decisão, a antecipação do resultado da estratégia. Isso não significa que Sêneca detivesse "direitos de autor" sobre a forma de composição do solilóquio, afinal ele mesmo seguia convenções literárias, mas é forte indício de que tais convenções foram assimiladas por Shakespeare e seus contemporâneos diretamente do modelo senequiano. Como afirmou T. S. Eliot em um de seus ensaios críticos, existe pelo menos um "odor de Sêneca" nos autores elisabetanos. ${ }^{15}$ Essa composição formular, calcada na tradição, deve estar refletida na tradução.

\section{The Tempest}

Estabelecer paralelos entre invocações a deuses ou a divindades em Sêneca e Shakespeare seria trabalho por demais extenso. Menções a Hécate, a divindade triforme à qual tantas vezes Medeia é associada, aparecem nos dramas ingleses com frequência, por exemplo, em Macbeth. Em Hamlet, ela é invocada pelo personagem Lucianus na peça concebida pelo príncipe, no Ato III cena 2 vv.256-61.

Em The Tempest, no entanto, a última invocação de Próspero antes de abandonar a magia evoca fortemente os versos iniciais da $\mathrm{Me}$ deia senequiana, que, por sua vez, ecoam as Metamorfoses, de Ovídio. No blend shakespeariano, a elocução transparece mais Sêneca (repetição insistente do vocativo) enquanto os tópicos são ovidianos (árvores arrancadas do solo, mortos que deixam os sepulcros), mas 
a ironia que perpassa a fala de Próspero é original. Os poderosos deuses dos poetas latinos resumem-se a divindades menores - elfos e duendes - em Shakespeare: Weak masters though ye be.

\section{MEDEIA, vv.1-12}

Di coniugales tuque genialis tori, Lucina, custos quaeque domituram freta

Tiphyn nouam frenare docuisti ratem,

et tu, profundi saeue dominator maris,

clarumque Titan diuidens orbi diem, tacitisque praebens conscium sacris iubar

Hecate triformis, quosque iurauit mihi

deos Iason, quosque Medeae magis

fas est precari: noctis aeternae chaos,

auersa superis regna manesque impios

dominumque regni tristis et dominam fide meliore raptam, uoce non fausta precor.
Deuses conjugais e tu, Lucina, guardiã do leito nupcial, e tu que ensinaste Tífis a conduzir a nova nau que domaria os mares, e tu, severo dominador do mar profundo, e Titã, que reparte pelo mundo o luminoso dia, e Hécate triforme, que exibe seu brilho cúmplice a rituais silentes, e os deuses pelos quais Jasão a mim fez uma jura e aqueles que é mais lícito que Medeia invoque: Caos da noite eterna, reinos inversos dos céus e manes impiedosos, senhor do triste reino e sua senhora cujo rapto foi mais fiel - os invoco sem fausto.

\section{THE TEMPEST, V, vv.1984-2008 PROSPERO}

Ye elves of hills, brooks, standing lakes, and groves, And ye that on the sands with printless foot 
Do chase the ebbing Neptune, and do fly him When he comes back; you demi-puppets that By moonshine do the green sour ringlets make Whereof the ewe not bites; and you whose pastime Is to make midnight-mushrooms that rejoice To hear the solemn curfew, by whose aid -Weak masters though ye be -- I have bedimmed The noontide sun, called forth the mutinous winds, And 'twixt the green sea and the azured vault Set roaring war; to the dread-rattling thunder Have I given fire, and rifted Jove's stout oak With his own bolt! The strong-based promontory Have I made shake, and by the spurs plucked up The pine and cedar. Graves at my command Have waked their sleepers, ope'd, and let 'em forth By my so potent art. But this rough magic I here abjure, and when I have required Some heavenly music, which even now I do, To work mine end upon their senses that This ayrie charm is for, I'll break my staff, Bury it certain fathoms in the earth; And deeper than did ever plummet sound, I'll drown my book.

\section{Considerações finais}

É uma teia extensa, tecida a muitas mãos, a literatura. Não é pelo mero passatempo de rastrear indícios da possível "influência" de outros autores que se debruçam tantos pesquisadores sobre a obra de Shakespeare, mas porque ele foi - e é ainda - veículo de transmissão de procedimentos literários que se provam, assim, universais no tempo e no espaço. Quando um dramaturgo como o alemão Heiner Müller (1929-1995) recria Hamlet em sua peça Hamlet Machine e faz o mesmo com Medeia em Margem Abando- 
nada Medeiamaterial Paisagem com Argonautas está dizendo que há um fundamento na criação humana que é inesgotável e, talvez, inalcançável, mas que é sempre preciso tentar.

\section{Notas}

1. Em Portugal, foi publicada, em 2011, tradução da professora da Universidade de Lisboa Ana Alexandra Alves de Souza, disponível também online: https:// bdigital.sib.uc.pt/jspui/handle/123456789/69.

2. Para uma visão geral do tema, ver a dissertação de CLOSEL, R.A.B.: www. bibliotecadigital.unicamp.br/document/?view $=000839344$.

3. Ver, por exemplo: http://www.electrummagazine.com/2010/12/shakespeare-and-the-classics-plutarch-ovid-and-other-sources/.

4. Ver o artigo de WAKELIN, D. (2008) em: http://www.jstor.org/stable/20464334.

5. Horácio, para Hamlet, representaria esse cidadão. Cf. Hamlet, Ato III, cena 2, vv.65-69: "Dá-me esse homem / que não se torna escravo da paixão, / e eu o trarei no fundo do meu peito, / no coração do próprio coração, / como eu te tenho." Trad. Barbara Heliodora. Ver Introdução da tradutora, p.25.

6. Para a mais recente visão sobre o tema, ver KER e WINSTON (2012).

7. Disponível em http://www.bartleby.com/359/16.html.

8. Ver Shakespeare (2010), especialmente p. 108, n. 60. 
9. O que se pode constatar ao comparar excertos de Sêneca a um trecho da Carta a Ático 1.16, em que Cícero reproduz uma argumentação com Clódio, no Senado.

10. Medeia, vv.170-1; Tiestes, v.257. A única ocorrência supérstite no teatro grego antigo é no Filoctetes, de Sófocles, v.753, mas com uma função apenas fática.

11. Optou-se por não adotar tradução para o português dos excertos de Shakespeare. Adotou-se o texto original da Royal Shakespeare Company (RSC), edição de Jonathan Bate e Eric Rasmussen, exceto The Tempest.

12. Ver a edição da RSC (2008, p. 141).

13. São minhas as traduções de Medeia neste artigo.

14. Sigo (PAVIS, 2008, p. 366).

15. (ELIOT,1967, p. 96): Seneca in Elizabethan Translation.

\section{Referências}

BALDWIN, T. W. William Shakespere's Small Latine \& Lesse Greeke. Urbana (EUA): University of Illinois Press, 1944. Disponível em: http://durer.press.illinois.edu/baldwin/index.html.Acesso em: 23 out. 2012.

ELIOT, T. S. Selected essays. Londres: Faber \& Faber, 1966.

KER, James; WINSTON, Jessica (Ed.). Elizabethan Seneca: Three tragedies. Londres:The Modern Humanities Research Association, 2012. 
MOMIGLIANO, Arnaldo. As raízes clássicas da historiografia moderna. Trad. Maria Beatriz Borba Florenzano. Bauru (SP): EDUSC, 2004.

PAVIS, Patrice. Dicionário de Teatro. Tradução dirigida por J. Guinsburg e Maria Lúcia Pereira. São Paulo: Perspectiva, 2008.

Retórica a Herênio. Tradução Ana Paula Celestino Faria e Adriana Seabra. São Paulo: Hedra, 2005.

SENECA. Medeia. Introdução e tradução H. M. Hine. Londres: Aris \& Phillips, 2007.

SHAKESPEARE. O primeiro Hamlet - in-quarto de 1603. Tradução de José Roberto O'Shea (Org.). São Paulo: Hedra, 2010.

. Hamlet, Rei Lear, Macbeth. Tradução de Barbara Heliodora e Anna Amélia de Queiroz Carneiro Mendonça. São Paulo: Editora Abril, 2010.

. The Tempest. WHITTED, Brent; YACHNIN, Paul (Ed.). Disponível em: http://internetshakespeare.uvic.ca/Library/Texts/Tmp/M/default/. Acesso em: 04 fev. 2013.

WINSTON, Jessica. Seneca in early Elizabethan England. In: Renaissance Quartely, v. 59, $\mathrm{n}^{\circ} 1$, p. 29-58, Spring, 2006.

Recebido em: 18/09/2013

Aceito em: 20/01/2014 